\title{
ÁREAS VERDES DE RECREAÇÃO
}

\section{GREEN SPACES AND RECREATION}

\section{Rosa Grena Kliass}

Arquiteta paisagista, mestre FAUUSP, fundadora e ex-presidente da Associação Brasileira de Arquitetos Paisagistas - ABAP.

\section{Miranda Martinelli Magnoli}

Professora titular da Faculdade de Arquitetura e Urbanismo da Universidade de São Paulo (FAUUSP). E-mail:mmemm@uol.com.br 


\section{RESUMO}

Esta é a reprodução de um texto mimeografado, extraído do relatório que originou o muito divulgado, mas pouco conhecido, Plano de Áreas Verdes, elaborado por Rosa Grena Kliass, Miranda M. Magnoli e equipe, ao final dos anos 1960, para a prefeitura de São Paulo. Esse foi um marco significativo, em termos de posturas teórico-metodológicas e de projeto, para os espaços livres públicos da cidade. Sua inserção na íntegra nesta publicação, à guisa de documento, objetiva trazer a público, dúvidas, certezas e posturas geradas, na época, sobre o assunto.

Palavras-chave: Espaços livres, áreas verdes, áreas de recreação, sistema.

\section{ABSTRACT}

This is a completely reproduction of an original paper from the 1960's years, which is an abstract of the research about the São Paulo green areas, developed by Rosa G. Kliass, Miranda Magnoli and team. This research is like a landmark in the brazilian landscape studies and had totally chanced the action of the São Paulo municipality about their open spaces.

Key words: Open spaces, green areas, recreational areas, and system. 


\section{ÁREAS VERDES DE RECREAÇÃO}

\section{GREEN SPACES AND RECREATION}

Espaços livres, projetos e comunicação

Administração: Faria Lima

Contrato: n. 6/67/SSM | folha n. 1 | obra levantamento: características

Autores: Rosa Grena Kliass e Miranda Martinelli Magnoli

Colaboração: Sérgio Souza Lima / Cemaco / Edith G. de Oliveira / Maria Maddalena Ré

São Paulo 10/fevereiro/1969

\section{Introdução}

conceito urbanístico de espaço livre está intimamente ligado à vida das cidades; estas são sentidas por suas ruas, praças e parques, que caracterizam a paisagem urbana.

Além de simples e indispensável elemento de regularização do grau higrométrico da atmosfera, eliminação de toxinas, equilíbrio de camadas de ar poluído, de abertura de áreas de luz e sol, os espaços livres têm significado muito maior: é um bem público onde, além de promover-se o reencontro do homem com a natureza, desenvolvem-se as atividades urbanas, com seus ritmos, em todas as escalas, desde a ida diária ao trabalho, à escola, às compras, o passeio domingueiro até a percepção da mudança das estações do ano.

Nossa população urbana é essencialmente de origem agrícola. Seus elementos, vindos de nossos campos e de emigração, vindos de zonas agrícolas de seus países de origem, trouxeram consigo a imagem da situação econômica precária a que fugiam, vinculada ao trabalho agrícola, ao verde. Este passou a ser identificado com dinheiro perdido, enquanto a urbanização vista como asfalto e concreto, dinheiro ganho.

Entretanto, a exigência humana de, no mínimo, manter um contato com os elementos da natureza é comprovada pela inusitada demanda e mesmo congestionamento dos meios de transporte intermunicipais em fins de semana e feriados; pela venda, a prestações irrisórias de lotes pequeníssimos em praias e serras longínquas, e pelas varandas mirins cheias de latas de plantas.

Até hoje, e visto é um traço característico de nossa cultura, vemos o verde, a piscina, o espaço equipado para jogos e esporte, como bens de luxo, acessíveis a uma minoria. É notória a tendência, no público, de obter esses bens por meio de uma competição individual que isola o problema de suas implicações de estrutura e de urbanização social. Esse enfoque do problema impede que o mesmo seja resolvido pela reinvidicação geral de caráter social visando a uma utilização comum dos espaços públicos.

O homem que vive nas cidades tem sua existência condicionada ao equilíbrio entre a satisfação das exigências individuais e ao grupo social a que pertence. 
Em grupos sociais de maior poder aquisitivo, há aspiração de melhoria do padrão de vida, que se dispersa em indiscriminada e improfícua corrida ao consumo de bens individuais, ao invés de traduzir uma cultura de participação de cada vez mais amplo interesse social, é devida à falta de atuação do poder público.

De outro lado, junto dos grupos sociais menos favorecidos, é preciso que o poder público crie condições de utilização dos espaços livres, pois que isto se constitui em um dos direitos do cidadão.

A recreação não é um elemento supérfluo na vida urbana, pois dela depende o equilíbrio das outras atividades e "não se trata de luxo, mas de necessidade. Não é simplesmente uma cousa de que a criança gosta, mas algo que precisa pra crescer. É mais do que parte essencial de sua Educação: é parte essencial da lei do seu crescimento, do processo que a leva à Maturidade". "A responsabilidade de administrador moderno quanto à saúde pública não se pode considerar cumprida com a construção de hospitais e manicômios, e nem a sua função educativa com a realização de escolas e campos esportivos", mas deverá antes preocupar-se com a criação de condições de desenvolvimento de uma infância e uma adolescência física e mentalmente sadia, e manter o equilíbrio de toda a população por sistemas recreacionais condizentes com as reais necessidades criadas na vida urbana, deverão ser modificadas as características dos espaços livres.

Assim, fica claro que são os espaços livres um dos fatores de maior importância para a polarização das atividades urbanas, visando a uma nova coesão social. "O espaço aberto da vida coletiva apresenta-se, pois, para nós, como um órgão da vida democrática e o primeiro instrumento urbano para a tomada de consciência social tão necessária para a dinâmica civilizatória."

\section{Espaços Livres em São Paulo}

A situação precária das áreas verdes e da recreação de São Paulo é sobejamente conhecida por administradores, arquitetos e urbanistas.

A falta de reinvidicação popular nesse campo, junto do poder público, não reflete o grau de necessidade da população nesse setor, pois ainda não foi criada a consciência do problema em suas reais dimensões: não se reinvidica o que não se conhece. Muito esparsamente, no entanto, essas reinvidicações começam a aparecer em alguns setores:

1 - Solicitações específicas à prefeitura por parte de sociedades de amigos de bairros e outras organizações comunitárias;

2 - artigos em jornais, sejam reinvidicatórios, sejam de aplauso à atuação da prefeitura;

3 - Iniciativas populares espontâneas criando um uso dos espaços verdes existentes, mas não equipados (o grande número de campos de futebol e clubes de malha).

A carência de espaços verdes é explicada por muitos fatores, mas principalmente pela especulação imobiliária que vem moldando toda a paisagem urbana paulistana e pela incapacidade dos governos municipais até hoje de atuarem na política dos espaços verdes.

Inicialmente a urbanização foi-se processando por loteamentos sem exigências quanto a espaços livres, criando em torno ao núcleo central e aos primeiros aglomerados de bairros uma feição desumana (por exemplo: Brás, Bom Retiro, Barra Funda, Bela Vista, etc.).

A primeira iniciativa por parte do poder público foi a criação da lei de loteamento, exigindo 10\% 248 da área total como doação à prefeitura para espaços verdes. Essa lei não vincula os espaços verdes à densidade demográfica ou ao volume de construções e não exige condições mínimas das áreas doadas, tais como dimensões, topografia, etc. Daí a situação dos espaços verdes nessas áreas "privilegiadas": pequenas áreas aproveitando cantos de quadra ou na intersecção 
de vias públicas e as maiores somente onde a topografia não permite um parcelamento em lotes: barrancos e fundos de vale com córregos.

Quando a prefeitura começou a atender a população com escolas municipais, parques infantis, centros recreacionais, prontos-socorros, bibliotecas, etc., utilizou-se do método mais imediato: localizou essas instituições sobre os espaços verdes disponíveis agravando ainda mais as condições precárias de nossa cidade.

Verifica-se a ausência quase total de parques metropolitanos em São Paulo. A demanda desses parques é clara quando se verifica a utilização que está sendo feita das áreas para piqueniques na via Raposo Tavares, a grande afluência de paulistanos às praias em fins de semana, a grande aceitação por uma camada da população da solução de clubes de campo, etc. É preciso que se processe imediatamente o aproveitamento dos vales dos rios Pinheiros e Tietê, das áreas em torno da represa de Guarapiranga, de Mata da Cantareira e do Parque do Estado.

\section{Metodologia}

\section{Coleta de Dados}

- Planta da cidade - esc. 1:20.000

- Geobrasil

- Planta da cidade - esc. 1:10.000

- Light

- Planta da cidade - esc. 1: 2.000

- Aerofotogramétrica CAP

- Planta da cidade - sem escala

- Planta Genérica D. Oficial

- Plantas de arruamentos oficiais

- Departamento de Urbanismo/PMSP

- Projetos Córrego da Mooca e Tatuapé - Departamento de Urbanismo/PMSP

- Plano Pré-Urbanístico do Vale do

Tietê ( J. Wilheim)

- Projetos de Espaços Livres

- Demografia - 1950-1960-1970-1980

- Classes Sociais

DAEE

- Divisão Distrital

- DAEE

- Censo Escolar (grupos etários)

- DEE

- Clubes de Malhas e Futebol

- DEE

- Localização de Escolas, Parques Infantis,

Bibliotecas, Centros Recreacionais

- Cons. Municipal de Esportes

- Coleta do lixo

- FECE

- SERV-PMSP

- Plano preliminar de Santo Amaro

- Neves e Paoliello

- Distribuição das ruas pavimentadas

O.

- Projetos de novos melhoramentos

- Departamento de Urbanismo da PMSP

- Plano Urbanístico Básico

- Asplan

- Divisão das zonas em setores limitados por acidentes topográficos ou por vias de trânsito intenso.

- Análise dos espaços livres em si: localização em relação a vias de grande trânsito, topografia, dimensão, etc., e caracterização das funções a que poderiam atender. 
- Análise quantitativa dos espaços livres existentes: cálculo de déficit de espaços livres equipados para recreação ativa nos diferentes grupos etários (0-5; 6-10; $11-14$; maiores de 15 anos) para 1980.

\section{Pesquisa Bibliográfica}

Verde per le Cittá: Ghio Calzolari

Pinheiros, aspectos geográficos de um bairro paulistano:

Departamento de Geografia

Faculdade de Filosofia, Ciências e Letras

Relator Geral: Pasquale Petrone

São Paulo, Metrópole 65: Jorge Wilheim

Espaços Urbanos: $\quad$ Francisco Riopardense de Macedo

Revista do EEUA. n. 1, URGS

Roma: verso um sistema generale del verde:

Urbanística, 46. 47/1966

Problèmes d'urbanisme: Gordon Cullen

\section{Visitas ao Local para Verificação de}

a. Influência do sistema viário na utilização de parques de vizinhança;

b. influência de acidentes topográficos na utilização dos espaços livres;

c. influência do tipo e da densidade de ocupação do solo na utilização e prioridade dos espaços livres;

d. influência da densidade demográfica na prioridade de utilização dos espaços livres;

e. influência dos níveis socioeconômicos da população, prioridade de utilização dos espaços livres;

f. espaços não-comprometidos para provável utilização como espaços livres.

Pesquisa sociológica paralela para obtenção de subsídios para o planejamento dos espaços livres em cinco zonas da cidade de São Paulo (Cemaco).

Para facilidade de elaboração do trabalho o município foi dividido em 25 zonas. Essa divisão tem apenas função metodológica e não corresponde a nenhuma divisão administrativa existente.

\section{Análise da Situação}

Foram locados todos os espaços livres de propriedade municipal, destinados a parque. Essa locação se baseou pela verificação in loco e nos desenhos dos arruamentos arquivados no Departamento de Urbanismo da Prefeitura de São Paulo.

Procedeu-se à caracterização dos mesmos pela indicação da superfície, da topografia e de observações particulares a cada um, tais como: manutenção, existência de construções, rios, córregos, etc.

Esses dados constam de "relações de áreas verdes" anexas a cada uma das zonas.

Constatou-se a existência de 3.260 espaços livres, completando 2.670 ha, dos quais somente 210 são tratados, sendo todos os demais terrenos baldios.

Os espaços livres existentes correspondem a um índice em potencial de 4,8 $\mathrm{m}^{2}$ por habitante. 
Foram locados todos os parques infantis, bem como as escolas públicas municipais, as bibliotecas municipais, os centros recreacionais da prefeitura e os clubes de malha e campos de futebol.

Considerou-se como clube de malha e campo de futebol a existência, por mais precária que fosse, de área com as utilizações indicadas, em vista que isto vem demonstrar parte da necessidade da população, constatável pelo surgimento espontâneo de campos esportivos.

Foi constatada a existência de 280 campos de futebol e 180 campos de malha e bocha.

Foram locados todos os melhoramentos previstos e aprovados, tais como novas avenidas, e foram levados em consideração a nova rede de freeways previstos pela PUB e a rede do metrô.

Foram caracterizadas as áreas da cidade de nível socioeconômico alto e médio alto para efeito de utilização de áreas verdes de recreação.

Essa caracterização foi procedida pela verificação in loco de elementos tais como: habitações de alto padrão com baixa ocupação de solo, com tratamento das áreas internas nos lotes (exemplo: Morumbi, Chácara Flora, etc.).

As áreas de níveis socioeconômicos alto e médio alto de alta densidade também foram caracterizadas com vistas a soluções de caráter legislativo.

Foram indicadas as áreas de uso do solo predominantemente comercial, industrial ou mista, bem como as áreas em franca modificação, pelas verificações in loco.

\section{Proposta}

\section{Classificação dos Espaços Livres}

I - Parque de vizinhança

II - Parque de bairro

III - Parque setorial

IV - Parques metropolitanos

V- Espaços livres especiais:

a) junto de centros de compras;

b) junto de centros cívicos;

c) junto de monumentos;

d) junto de edifícios públicos (inclusive escolas);

e) junto de vias de trânsito intenso (avenidas, parques).

I. Parque de vizinhança - são áreas verdes destinadas à recreação ativa de crianças de 0 a 10 anos e à recreação passiva. Seu raio máximo de atendimento é 500 m, sem travessia de ruas de trânsito intenso.

II. Parque de bairro - são áreas verdes destinadas à recreação ativa de jovens de 11 a 24 anos e à recreação passiva. Seu raio máximo de atendimento é 1.000 m.

III. Parque setorial - são áreas verdes destinadas à recreação ativa e passiva de toda a população do município, com equipamentos para utilização em fins de semana, com um raio de atendimento máximo de $5.000 \mathrm{~m}$.

IV. Parques metropolitanos - são áreas verdes destinadas à recreação ativa e passiva de toda a região metropolitana, localizados nas reservas florestais junto de represas, etc. 
As nossas propostas são feitas para 1980 e abrangem somente os parques de vizinhança, parques de bairro e parques setoriais, pois a quantificação e distribuição dos parques metropolitanos e dos espaços livres especiais dependem de elementos que não estão a nosso alcance: índices de áreas verdes para toda a Grande São Paulo e planos urbanísticos detalhados já com sistema escolar, sistema viário definidos.

Foram utilizados para este trabalho o Plano Urbanístico Básico, o Plano Urbanístico do Vale do Tietê e o Plano Preliminar de Santo Amaro.

município foi dividido em áreas segundo a possibilidade de intervenção da seguinte forma:

1. Zonas especiais: estas áreas foram por nós consideradas não-passíveis de intervenção por estarem em franca mobilidade de uso de solo ou por exigirem planos setoriais para definição. São zonas predominantementes industriais, comerciais, residenciais intensivas e as zonas sem definição clara de uso do solo por transformações às quais estão sendo submetidas por planos ou espontaneamente.

2. Zonas de residências de nível médio-alto e alto: a estas zonas de nível médio-alto não foram feitas propostas de parques de vizinhança, considerando-se que a recreação infantil pode ser realizada dentro dos próprios lotes.

Para as zonas de nível alto não foram feitas propostas de parques de vizinhança e parques de bairro, considerando-se que a recreação juvenil seria dentro do próprio lote.

Além da consideração do tamanho do lote, levou-se em conta que a população de níveis médioalto e alto têm condições de recreação em clubes, casas de campo e praias.

3. Zonas residenciais estáveis: para estas zonas foram feitas propostas de parques de vizinhança e parque de bairro.

\section{Quantificação e Distribuição}

A quantificação das áreas verdes de recreação foi feita a partir de dados e critérios adotados:

1 - Demografia: densidade, porcentagem dos grupos etários, níveis sociais;

2 - vias de trânsito;

3 - raios máximos de atendimento:

$500 \mathrm{~m}$ - Parque de vizinhança

$1.000 \mathrm{~m}$ - Parque de bairro

$5.000 \mathrm{~m}$ - Parque setorial

4 - Índice de freqüência dos grupos etários:

$0-10$ anos $-1 / 3$

$11-15$ anos $-1 / 3$

$16-24$ anos $-1 / 5$

(para parques setoriais) - 1/10;

5 - Área total de parque necessária por usuário para diferentes grupos etários:

0 - 10 anos - 22,5 $\mathrm{m}^{2} /$ usuário

11 - 15 anos - 45,0 m²/usuário

16 - 24 anos - 120,0 m²/usuário (para parques setoriais) - 100,0 m²/usuário.

Chegou-se a um valor b global de 10.373 ha de áreas verdes para recreação para 1980 e que equivale a um índice de 12,4 $\mathrm{m}^{2} /$ hab., assim distribuídos: 
Parques de Vizinhança

Parques de Bairro

Parque Setorial
- $1.832,63 \mathrm{ha}-2,2 \mathrm{~m}^{2} / \mathrm{hab}$.

- 2.164,35 ha $-2,6 \mathrm{~m}^{2} / \mathrm{hab}$.

- 6.370,05 ha $-7,6 \mathrm{~m}^{2} /$ hab.

Como os critérios acima expostos, não foram utilizados os espaços livres municipais disponíveis, na medida em que não tinham condições de utilização, ou por não terem suficiente dimensionamento e condições topográficas, ou por má distribuição.

Para os parques propostos em terrenos a serem desapropriados o critério adotado foi o de aproveitamento de terrenos vazios, sem loteamento, quando possível, ou vazios sem construções.

No caso em que não se teve condições de escolher o local pelo fato de a área apresentar-se totalmente ocupada, indicou-se a localização ideal de parque e a área necessária.

Foram propostos parques de vizinhança com um mínimo de $2.000 \mathrm{~m}^{2}$ e em locais de topografia acidentada de $8.000 \mathrm{~m}^{2}$ e o máximo de $25.000 \mathrm{~m}^{2}$.

Os parques de bairro propostos apresentaram-se sempre junto de parques de vizinhança.

Para os parques setoriais foram considerados os parques existentes ampliados quando necessário; propôs-se parte das reservas florestais ou das áreas de preservação junto de represas, as áreas do Vale do Tietê e indicados novos parques setoriais nas zonas em que aqueles não suprimem.

Além das indicações das desapropriações, fazemos as seguintes recomendações aos órgãos públicos:

a. Organizar campanha de divulgação para:

- conscientizar a população das necessidades de parques públicos;

- orientar a população quanto a seu uso;

- conseguir um grau de entrosamento com os demais órgãos públicos e organizações comunitárias (sociedade de amigos de bairro, sociedade de amigos da cidade, Rotary, Lyons, etc.) que venham contribuir sensivelmente para crescente melhoria do problema de parques públicos;

b. tomar providências urgentes para, desde já, impedir não somente construções clandestinas nos espaços livres, mas também construções públicas mesmo de caráter prioritário, tais como educativos ou de saúde;

c. tomar providências para conseguir novos espaços livres nos setores deficitários, nas proporções indicadas, levando em conta o caráter do déficit: quantitativo, qualitativo e de locação quanto ao seu raio de influência (déficit de distribuição);

d. criar condições para que o plano diretor possa controlar a ocupação do solo de modo a resolver a falta de espaços livres, especialmente em áreas de franca mobilidade;

e. criar condições para que o órgão público venha a exigir espaços livres com determinadas características de locação, dimensionamento e topografia;

f. atender prioritariamente:

1. Parques de Vizinhança

2. Parques de Bairro

3. Parques Setoriais 


\title{
Histórico das Atividades da "Equipe de Espaços Livres - Projetos e Comunicações"
}

\author{
Rosa Grena Kliass
}

\author{
Miranda Martinelli Magnoli
}

Abrahão Sanovicz

Tendo havido modificações nos quadros da Administração Superior durante o andamento dos trabalhos do Contrato n. 6/67/SSM, é de capital importância a apresentação deste histórico, a fim de que possam ser avaliados os resultados dos trabalhos elaborados pela equipe contratada.

Por solicitação do chefe da então Divisão de Parques, Jardins e Cemitérios, doutor Rubens Martinelli Fachini, em maio de 1966, deu-se início a um estudo de plano de trabalho para elaboração de praças para a prefeitura municipal de São Paulo, pelos arquitetos Rosa Grena Kliass, Miranda Martinelli Magnoli e Abrahão Sanovicz.

Após exaustiva análise das alternativas optou-se, de comum acordo com o então secretário de Serviços Municipais doutor João Moreira Garcez e o chefe de divisão doutor Rubens Martinelli Fachini, por um plano global em que, segundo um contrato de serviços, a equipe apresentada, além de projetos de praças com um elenco de equipamentos passíveis de pré-fabricação em série, o planejamento dos viveiros municipais, o levantamento dos espaços livres disponíveis, além de um programa de comunicação visual.

Esse plano foi apresentado em carta proposta endereçada ao senhor prefeito, em 5 de novembro de 1966, na qual, além do plano de trabalho, eram fornecidos valores de honorários por estimativa de horas de trabalho de pessoal e despesas para os diferentes itens.

Com base nessa carta proposta, foi elaborado pela prefeitura, com assessoria do doutor José Luiz Rubião de Sá, assistente jurídico de SSM, o contrato de serviços 6/67/SSM, de 22 de março de 1967, de 6 meses, prorrogáveis para 24 meses, desde que avaliada a conveniência para o órgão municipal. Foram utilizados, nesse contrato, os valores de honorários e despesas fornecidos em novembro de 1966 na carta proposta referida no parágrafo anterior.

Como rezava o contrato foi elaborada, com a prefeitura, uma programação dos trabalhos a serem executados pela equipe, programação esta que, após sua aprovação pela PMSP, passou a ser peça contratual (documento denominado "Programação" - Fls. P/1 a P/19).

A programação foi cumprida integralmente, seguindo os prazos contratuais, e os trabalhos entregues foram aprovados pelos arquitetos designados pela prefeitura.

Findos os 6 primeiros meses, a PMSP houve por bem autorizar a prorrogação dos trabalhos para 24 meses por despacho do senhor prefeito em 12/09/1967, conforme Ofício n. 9/67, do Departamento de Serviços Internos de SERV (documento de posse da equipe).

Novamente a equipe, de acordo com o contrato, elaborou com a prefeitura de São Paulo, a programação para os 18 meses subseqüentes. Para tal foram solicitadas relações de projetos de praças em elaboração em URBI, Parque 1 e o programa de PREF-CE. Verificou-se em PATRI a propriedade de PMSP de todas as áreas passíveis de constar na nova programação.

Esse documento "Programação" 2a etapa (fls. P/20 a P/30), devidamente aprovado por PMSP, passou também a fazer parte dos documentos contratuais. $O$ prosseguimento dos trabalhos, até a presente data, seguiu à risca os prazos estipulados (documentado pela equipe em relações de entrega de trabalhos) e teve sistematicamente aprovação em sua qualidade por parte dos arquitetos da prefeitura. Em casos de solicitação por parte de PMSP de abreviação dos prazos, os trabalhos correspondentes foram entregues antecipadamente (exemplo: Praça da Bandeira, avenida 23 de Maio, avenidas do Contorno, Auxiliar e Radial Norte, praça L. Vampré e parque da Vila Cachoeirinha - conjunto do IPESP). 
Vários trabalhos não-previstos na programação foram executados:

Remanejamento dos seguintes projetos devido ao corte de verba:

Terminal

Vila Jacuí

Mikado-Oyeno

Santo Eduardo

Benedito Calixto

Ouro

Campos Sales

Pedro I

Barão de Itaqui

Diogo do Amaral

Nossa Senhora do Bom Parto

Baúna

Novos projetos:

Praça Sold. Solano - por tardia (12 meses) informação da URBI - documentado.

Praça do Café - por informação errônea de PREF-CE - documentado.

- Coordenação dos trabalhos do grupo de projetos de instalação hidráulica e elétrica.

- Coordenação dos trabalhos do grupo e de orçamento.

- Levantamentos topográficos executados e pagos pela equipe, sem ônus para a PMSP e nãoutilizados: Praça Américo Jacomino (antigo E VII) - Comissão de URBI.

Área adjacente ao Museu do Ipiranga (antigo E 29) - informação errônea de PATRI.

- Partipação com despesas por conta da equipe nos stands de exposição da PMSP em Santos e Sorocaba.

- Artes-finais de dois cartazes impressos para a data festiva - Fundação de São Paulo, 1968.

- Projeto completo de fabricação e montagem de um quiosque de madeira para venda de jornais, de um sistema de coberturas para clubes de malhas e outras utilizações com projeto estrutural, memorial e especificações.

- Projeto e maquete de um marco para as entradas da cidade.

A prefeitura tem, no momento, condições de utilização imediata:

Projetos de 45 praças e quatro avenidas, sendo:

- Sete espaços destinados a centros de compras, centros de caráter social, com recreação passiva e/ou áreas ligadas a vias de trânsito (três em execução);

- 25 espaços destinados a centros de recreação ativa e passiva para jovens, crianças e adultos (nove em execução - três em concorrência);

- 11 espaços destinados a parques com playground e recreação passiva (três em execução um em concorrência);

- Dois espaços destinados a parques setoriais de grande porte.

- Projetos de equipamentos: 
completos, incluindo projeto estrutural, instalações hidráulicas e elétricas, memoriais e especificações de sanitários, caixas d'água, depósito, cabine telefônica, abrigo de chuva, abrigos de sol, taças combináveis, elementos de separação de canteiros, três bancos, fechos devassáveis e indevassáveis, luminárias, sinalização (tipos e alfabeto standard para silk-screen), cestas de lixo, brinquedos para playground, quiosques, esculturas, mesa para piquenique, relógio para praças, bebedouro, pisos, caixas para plantas, tutor, grelhas para águas pluviais, hidrante, caixa postal, frades.

- Planejamento de viveiros.

- Projetos de comunicação para três datas festivas.

- Até o dia 10 de fevereiro terá a prefeitura um cadastramento completo dos espaços livres de propriedade municipal destinados a praças e parques?

\section{Nota}

(1) É parte integrante deste documento a Tabela de Recursos Despendidos e Atividades Realizadas, a qual foi considerada pela Comissão Editorial como irrelevante para efeito de documentação. Ela pode ser consultada no documento original existente na Biblioteca da Faculdade de Arquitetura e Urbanismo da Universidade de São Paulo (FAUUSP). 